\title{
Os Vínculos que o Indivíduo Estabelece com A Organização: uma análise da Produção Científica brasileira
}

\author{
Bonds of the Individual with the Organization: an analysis of \\ brazilian scientific production
}

\section{Laércio André Gassen Balsan}

Doutorando em Administração. Universidade Federal de Santa Maria. Santa Maria, RS. Brasil. E-mail: laerciobalsan@yahoo.com.br

Jordana Marques Kneipp

Doutorando em Administração. Universidade Federal de Santa Maria. Santa Maria, RS. Brasil. E-mail: jordanakneipp@yahoo.com.br

\section{Stefania Tonin}

Doutorando em Administração. Universidade Federal de Santa Maria. Santa Maria, RS. Brasil. E-mail: stefaniatonin@gmail.com

\section{Vânia Medianeira Flores Costa}

Doutora em Administração. Professora do Programa de Pós-graduação em Administração da Universidade Federal de Santa Maria.

Santa Maria, RS. Brasil. E-mail: vaniaflores2006@yahoo.com.br

\section{Resumo}

Este estudo analisou a produção científica brasileira do indivíduo com a organização vinculada aos eventos e periódicos da Associação de Programas de Pós-Graduação em Administração (ANPAD), no período de 1997-2013. Foram encontrados 145 artigos sobre os temas "comprometimento, entrincheiramento e consentimento organizacionais." As publicações ocorreram em maior número a partir de 2007. As instituições que mais se destacaram foram a Universidade Federal da Bahia, Universidade Federal de Minas Gerais e Universidade Federal do Rio Grande do Norte. Os artigos analisados são em sua maioria empíricos, predominando a abordagem quantitativa e estão relacionados principalmente ao setor prívado. Os resultados contribuem para a construção do conhecimento científico sobre os vínculos organizacionais, uma vez que demonstraram as principais características e tendências com relação às publicações acadêmicas sobre o assunto no Brasil.

Palavras-Chave: Comprometimento Organizacional. Entrincheiramento Organizacional. Consentimento Organizacional. Vínculos Organizacionais.

\section{Abstract}

This study analyzes the Brazilian scientific production, related to events and periodical of the Association of Graduate Programs in Business Administration (ANPAD) in the period 1997-2013 on bonds of the individual with the organization. Were found 145 papers on themes about organizational commitment, entrenchment and consent. It was found that the publications were more frequent from 2007. Institutions that stood out were the Federal University of Bahia, Federal University of Minas Gerais, Federal University of Rio Grande do Norte. The articles are analyzed in its most empirical, predominantly quantitative approach and are related mainly to the private sector. The results contribute to the construction of scientific knowledge about the organizational links, once they showed the main features and trends in relation to academic publications on the subject in Brazil.

Keywords: Organizational Commitment. Organizational Entrenchment. Organizational Consent. Organizational Linkages. 


\section{INTRODUÇÃo}

O comprometimento com a organização é um dos temas relacionados ao comportamento organizacional, é o mais investigado, tanto no Brasil como no exterior. Mesmo assim, ainda existe grande confusão conceitual cercando o constructo (BASTOS et al., 2009; RODRIGUES; BASTOS, 2010; RODRIGUES, 2011). Grande parte da discussão acerca da confusão conceitual gira em torno do modelo proposto por Meyer e Allen (1991), o qual, a partir da década de 1990, tornou-se o principal modelo para medir o comprometimento do individuo com a organização. Foi partindo dos problemas conceituais que cercam o construto tridimensional que Bastos et al. (2009) e Rodrigues (2009) propõem o conceito de entrincheiramento organizacional e que Silva (2009) propõe o conceito de consentimento organizacional.

O entendimento de tais conceitos e de sua dinâmica é de extrema importância na construção de práticas organizacionais que visem a uma melhor adequação do comportamento humano ao contexto de trabalho. A fim de ampliar o conhecimento sobre a produção científica relacionada aos vínculos organizacionais, este estudo teve por objetivo analisar as publicações vinculadas ao tema nos eventos e periódicos da Associação de Programas de Pós-Graduação em Administração (ANPAD), no período de 1997 a 2013, abrangendo três temas principais: comprometimento organizacional, entrincheiramento organizacional $e$ consentimento organizacional. Justifica-se essa escolha pela importância dessas questões para o campo de pesquisa sobre comportamento organizacional e a intensa concentração de pesquisa sobre o tema. Para tanto, realizou-se uma pesquisa de caráter bibliométri$\mathrm{co}$, na qual se buscou artigos relacionados às palavras-chave: "comprometimento", "entrincheiramento" e "consentimento", resultando em 173 artigos. Foram utilizadas essas palavras, pois dessa forma o pesquisador poderia ter acesso a um número maior de artigos do que se fosse usada a palavra "comprometimento organizacional”, por exemplo. Nesse caso, não seriam retornados resultados como: comprometimento afetivo, comprometimento com a organização, comprometimento normativo, entre outros.

Após uma análise preliminar e a consideração de que o foco deste estudo são os vínculos com a organização, foram desconsiderados os artigos sobre comprometimento com a carreira (sete artigos), comprometimento do consumidor (dez artigos), comprometimento de recursos (um artigo) e comprometimento com o meio ambiente (um artigo). Ainda foram desconsiderados nove que se repetiram devido às buscas sucessivas realizadas com as diferentes palavras-chave. Assim, a amostra deste estudo ficou constituída por 134 artigos publicados nos eventos e 11 nos periódicos, totalizando 145 artigos.

Este artigo divide-se em cinco seções e apresentará, além da introdução, uma contextualização sobre os vínculos que o indivíduo estabelece com a organização; a seguir, evidencia-se o método utilizado para o desenvolvimento do presente estudo; após, apresenta-se a análise dos dados e discussão dos resultados e, por fim, as considerações finais.

\section{Comprometimento Organizacional}

Os estudos sobre os vínculos do indivíduo com a organização têm sido objeto de interesse de pesquisadores e gestores. Dessa forma, pesquisas ocuparam-se em estudá-los e em examinar seus antecedentes e consequentes, para a compreensão de seu quadro teórico e desenvolvimento de práticas de gestão (RODRIGUES et al., 2013). Dentre esses vínculos, o comprometimento organizacional busca entender como se articulam comportamentos dos indivíduos com seus trabalhos e empresas empregadoras (COSTA; BASTOS, 2009).

Para Mowday et al. (1979, p. 225), o comprometimento organizacional é "[...] um estado no qual um indivíduo se identifica com uma organização particular e com seus objetivos, desejando manter-se afiliado a ela com vistas a realizar tais objetivos". Sendo assim, esse vínculo possuiu uma força estabilizadora resultante de um estado ou esquema mental que direciona e restringe o comportamento do indivíduo a determinado curso de ação relevante para um ou mais objetivos (MEYER; HERSCOVITCH, 2001).

Bastos et al. (2008) afirmam que, como constructo comportamental, o comprometimento fundamenta-se na crença de que as pessoas se comprometem com ações e de que as atitudes são consequentes dos comportamentos. Para Rodrigues e Bastos (2010), os trabalhadores comprometidos apresentam engaja- 
mento e dedicação com a organização, além de zelo pelo setor em que atuam. Desse modo, para Bastos e Menezes (2009), o comprometimento pode ainda ser analisado a partir dos comportamentos adotados que extrapolam as expectativas constantes do contrato formal celebrado entre a organização $e$ o indivíduo.

Dentre as dimensões do comprometimento, o modelo tridimensional proposto por Meyer e Allen (1991) tem sido o mais investigado. Os autores apresentaram o comprometimento como um estado psicológico, composto por três bases distintas. A primeira delas é a base afetiva, pautada na identificação de valores, desejo de permanecer na organização e apego emocional, em seguida a base normativa como uma obrigação moral de continuar na empresa e, por fim, a base instrumental como uma necessidade, uma análise dos custos e benefícios associados à permanência ou à saída da organização.

Embora o modelo proposto por Meyer e Allen (1991) seja predominante nas pesquisas que avaliam o comprometimento organizacional, vem sendo alvo de questionamentos e críticas relacionadas à exatidão conceitual e à presença de elementos antagônicos na base conceitual do comprometimento (PINHO, 2009; RODRIGUES, 2009; RODRIGUES; BASTOS, 2010; MOSCON; SOUZA, 2010, RODRIGUES; BASTOS, 2011; NASCIMENTO 2013). Costa et al. (2008) evidenciam ainda que os estudos realizados não demostraram aspectos conclusivos acerca da validade do modelo no Brasil.

A evolução do próprio conceito de comprometimento ocorrida devido às mudanças econômicas, sociais, políticas e tecnológicas, a partir da revolução industrial, levaram a questionamento da dimensão instrumental do construto (BARROS, 2007). Se anteriormente os problemas de gestão enfrentados pelas organizações estavam relacionados à padronização, ao aumento produção relacionada ao salário e à rotatividade de pessoal, atualmente, juntam-se a estas questões aspectos relacionados ao desempenho, qualidade do trabalho $e$ resultados organizacionais. Além de reter os bons profissionais, as organizações esperam deles uma contribuição ativa. A permanência passiva não agrega valor às tarefas e à equipe (RODRIGUES; BASTOS, 2009).

Para Nascimento (2013), outro tema que tem instigado estudos relacionados com a base instrumental possui embasamento teórico na possibilidade de sobreposição conceitual entre o comprometimento instrumental e o entrincheiramento organizacional, construto que será abordado no tópico a seguir.

\section{Entrincheiramento Organizacional}

De acordo com Pinho et al. (2012), o vínculo de entrincheiramento tem origem nas pesquisas realizadas no campo de estudos das carreiras por Carson e Bedeian (1994) e Carson et al. (1995). O conceito de entrincheiramento foi introduzido pelos autores com o propósito de diferenciar o comprometimento com a carreira, campo de investigação ao qual o modelo tridimensional de Meyer e Allen (1991) foi estendido (PINHO et al., 2011).

Para Carson e Bedeian (1994) e Carson et al. (1995), o entrincheiramento na carreira é definido como uma decisão do profissional de seguir no mesmo campo de trabalho, devido à falta de alternativas, ao sentimento de perda dos investimentos já realizados e a percepção de um custo emocional alto em caso de mudança profissional. Sendo assim, o indivíduo tende a não trocar de emprego pelo temor de ser estigmatizado devido ao seu afastamento, o receio de perder seu prestígio profissional, de reduzir seu salário após o afastamento e até mesmo pelas dificuldades associadas às limitações de empregabilidade.

O construto de entrincheiramento foi adaptado para o contexto organizacional com base na proposta de Bastos et al. (2009), o que os autores denominaram de entrincheiramento organizacional. Conforme Pinho et al. (2012), a transposição sugerida pelos autores destaca a estabilidade do trabalhador na organização em função da falta de oportunidades, o que levaria a tratar a organização como uma trincheira na qual seria mantida a segurança e o status social. No entendimento de Bastos et al. (2009), se o profissional não percebe grandes custos associados a sua saída, não está entrincheirado, desse modo o indivíduo até pode pensar que há custos, mas acredita em outras oportunidades compensatórias.

Desse modo, Rowe e Bastos (2008) afirmam que o entrincheiramento é o comportamento profissional do indivíduo que prossegue em determinada linha de ação, por não visualizar outras opções, pela sensação de perda de investimentos já realizados, bem como pela 
percepção de que a mudança de emprego ocasionará grandes abalos emocionais.

Bastos et al. (2009) propuseram três dimensões com o intuito de medir o construto de entrincheiramento organizacional: ajustamento à posição social, arranjos burocráticos impessoais e limitações de alternativas. A primeira dimensão destaca os investimentos do indivíduo nas aptidões e condições necessárias para o trabalho, como cursos e treinamentos para desempenho de atividades específicas, tempo de aprendizado dos procedimentos organizacionais e as atribuições da função, relacionamentos construídos com colegas de trabalho, entre outros aspectos que contribuem para adequação do sujeito e que seriam perdidos caso deixasse a organização. Já os arranjos burocráticos impessoais atentam para a estabilidade financeira, os custos e os benefícios perdidos, se o indivíduo saísse da organização. Por fim, a limitação de alternativas denota a percepção de falta de opções no mercado de trabalho, caso o colaborador saísse da organização.

Rodrigues (2009) aprimorou o instrumento proposto para medir o vínculo, conservando as mesmas dimensões. Essa autora explica "[...] não é possível falar de uma permanência espontânea do trabalhador entrincheirado, mas sim em decorrência da sua necessidade" (RODRIGUES, 2009, p. 76). Desse modo, a essência do construto de entrincheiramento abrange a noção de estar aprisionado numa organização, por não conseguir visualizar alternativas que satisfaçam as expectativas e necessidades do indivíduo.

Além de o indivíduo permanecer na organização como forma de sentir-se seguro nas esferas econômica, social e emocional, também pode manter-se na empresa devido à formação de um vínculo de obediência, que será elucidado no próximo tópico.

\section{Consentimento Organizacional}

O consentimento organizacional sustenta-se teoricamente com base na literatura sociológica. Dessa forma, Pinho (2009) coloca que o vínculo entre o indivíduo e a organização não ocorre por meio de aspectos afetivos e psicológicos, mas sim, por relações de controle e autoridade que levam o trabalhador a obedecer ou desempenhar o papel de subordinado. Assim, no âmbito dos estudos sociológicos, o termo consentimento destaca a relação de subordinação entre empregador e empregados (PINHO et al., 2012).

Para Myers (2000), a obediência e o conformismo são universais, e é por meio da socialização cultural que as pessoas podem apresentar mais ou menos reação social. Em termos gerais, o autor coloca que o indivíduo obedece diariamente, então o que se procura entender é se as normas às quais as pessoas se conformam ou as ordens que acatam, refletem seus valores, respeitam seus direitos, o bem-estar e a dignidade humana. Esses aspectos são corroborados por Schwartz (2005), ao afirmar que a compreensão sobre os valores de conformidade e tradição fornece elementos para avaliar o processo de influência social, já que esses valores se referem ao comportamento individual e grupal $e$ levam em consideração fatores como história de vida, valores e crenças pessoais, normas sociais e aceitação de costumes e crenças valorizados pela cultura. Portanto, o consentimento pressupõe uma relação entre os valores individuais e culturais.

De acordo com Bastos et al. (2009), o consentimento organizacional integra-se a um comportamento passivo adotado pelo indivíduo em um determinado momento, sem autonomia, no qual as decisões estão condicionadas a uma influência de autoridade. Para o autor, uma atitude crítica, ativa ou contestadora é dificilmente vislumbrada, de modo que os indivíduos acatam ou consentem de forma "cega", "automática", não questionando o que lhes é imposto.

Silva (2009) coloca que o construto de consentimento organizacional é bidimensional, composto por duas dimensões: obediência cega e aceitação íntima. A primeira dimensão versa sobre o cumprimento automático da ordem, de modo que o indivíduo não avalia ou julga o comando recebido, pode indicar também que, mesmo não havendo entendimento sobre o significado da tarefa, o trabalhador a realiza. O indivíduo comporta-se conforme as ordens estabelecidas pelo seu superior hierárquico e não se considera responsável por nenhuma consequência - principalmente negativa - que possa ocorrer devido as suas ações. Com relação à dimensão de aceitação íntima, nota-se que o cumprimento das normas e das regras estabelecidas ocorre em função de uma concordância autêntica com elas. Desse modo, há semelhança entre as visões do indivíduo e da organização, o que conduz a uma identificação com as regras, os procedimentos e os valores que embasam as decisões dos gestores. 
Sendo assim, Pinho et al. (2012) alegam que a preocupação acerca do vínculo de consentimento encontra-se em responder à indagação em torno do cumprimento da função prescrita pelo indivíduo, bem como entender se quando o trabalhador cumpre seu papel prescrito, segue as normas e obedece aos seus superiores, ele se caracteriza com um trabalhador comprometido ou não. Além disso, há possibilidade de caracterizá-lo como um vínculo relacionado pelos valores da obediência e da subordinação à chefia.

A fim de contribuir para essas discussões que emergem no campo de estudos sobre vínculos organizacionais, a presente pesquisa procura analisar as publicações relacionadas ao tema comprometimento, entrincheiramento e consentimento organizacionais nos eventos e periódicos da Associação de Programas de Pós-Graduação em Administração (ANPAD), no período de 1997 a 2013. O método utilizado neste estudo encontra-se descrito a seguir.

\section{Método}

O presente estudo possui como objetivo analisar as publicações relacionadas ao tema "comprometimento, entrincheiramento e consentimento organizacionais" nos eventos e periódicos da Associação de Programas de Pós-Graduação em Administração (ANPAD), no período de 1997 a 2013, e caracteriza-se como exploratório e descritivo. Segundo Gil (2010), a pesquisa exploratória tem por finalidade ampliar o conhecimento a respeito de determinado fenômeno, explorando uma determinada realidade. Neste caso, pretende-se aprofundar a compreensão sobre a produção científica relacionada ao tema em questão. O estudo também possui caráter descritivo já que visa identificar, descrever e analisar a produção científica sobre o tema. Para Triviños (1987), esse tipo de estudo pretende descrever os fatos e fenômenos de determinada realidade.

A fim de atingir o objetivo proposto realizou-se um estudo bibliométrico, tendo em vista que foi analisada a produção científica sobre os vínculos organizacionais em um intervalo de tempo delimitado e em uma determinada unidade de análise. Segundo Silva (2004), a bibliometria possui como objetivo analisar a atividade científica ou técnica através do estudo quantitativo das publicações. Complementando essa ideia, Rostaing (1997) coloca que o estudo bibliométrico consiste na aplicação dos métodos estatísticos ou matemáticos sobre o conjunto de referências bibliográficas. Para Macedo, Casa Nova e Almeida (2007), a bibliometria ajuda a conhecer o estágio em que uma pesquisa em determinada área se encontra.

\subsection{Definição da Amostra}

A Associação Nacional de Pós-Graduação e Pesquisa em Administração (ANPAD) foi criada em 1976, com o objetivo de promover o ensino, a pesquisa $e$ a produção de conhecimento dentro do campo das ciências administrativas, contábeis e afins no Brasil. A ANPAD consiste no principal órgão de interação entre programas de pós-graduação, grupos de pesquisa e comunidade internacional, acolhendo distintas posições teóricas dentro do campo científico das ciências administrativas, contábeis e afins, figurando como importante espaço de diálogo e debates acadêmicos e de vivência social (ANPAD, 2009).

A fim de estimular discussões e reflexões acerca dos temas pertinentes no campo das ciências administrativas, contábeis e afins, a ANPAD delimitou Divisões Acadêmicas que reúnem vários temas de interesse científico. Esses temas correspondem amplamente às distintas esferas de que é constituída a administração tanto pública como privada e de organizações do terceiro setor, sendo eles: Administração da Informação, Administração Pública, Contabilidade, Estudos Organizacionais, Ensino e Pesquisa em Administração e Contabilidade, Estratégia em Organizações, Finanças, Gestão da Ciência Tecnologia e Inovação, Gestão de Operações e Logística, Gestão de Pessoas e Relação de Trabalho, Marketing (ANPAD, 2009).

A ANPAD realiza anualmente diversos eventos acadêmicos, no intuito de propiciar a professores, pesquisadores e estudantes a possibilidade de intercâmbio e troca de conhecimentos e experiências, como: Encontro da ANPAD (EnANPAD), Encontro de Marketing da ANPAD (EMA), Encontro de Estudos Organizacionais (EnEO), Encontro de Estudos em Estratégia (3Es), Simpósio de Gestão da Inovação Tecnológica da ANPAD - Simpósio, Encontro de Administração Pública e Governança da ANPAD (EnAPG), Encontro de Gestão de Pessoas e Relações de Trabalho (EnGPR), 
Encontro de Administração da Informação (EnADI), Encontro de Ensino e Pesquisa em Administração e Contabilidade (EnEPQ) (ANPAD, 2010a).

A Associação também possui alguns periódicos sob sua responsabilidade, sendo os seguintes: Revista de Administração Contemporânea (RAC), Brazilian Administration Review (BAR), RAC - Eletrônica (ANPAD, 2010b).

Dessa maneira, tendo por base a representatividade e amplitude dos eventos e periódicos da ANPAD na promoção e difusão do conhecimento acadêmico/ científico na área da Administração, foram delimitados como unidade de análise os anais de todos os eventos da ANPAD e os periódicos RAC, BAR e RAC - Eletrônica, no período de 1997 a 2013. Para tanto, utilizou-se como palavra-chave "comprometimento", "entrincheiramento" e "consentimento". A busca resultou em 134 artigos publicados nos eventos e 11 nos periódicos, totalizando 145 artigos.

\subsection{Modelo Conceitual}

O modelo conceitual utilizado neste estudo foi uma adaptação do modelo conceitual proposto por Pinto e Lara (2008), conforme Quadro 1.

\begin{tabular}{|l|l|}
\hline $\begin{array}{l}\text { Características gerais } \\
\text { Das publicações }\end{array}$ & \multicolumn{1}{c|}{$\begin{array}{c}\text { Aspectos metodológicos das } \\
\text { PUblicações }\end{array}$} \\
\hline - Ano da publicação & - Tipo de artigo \\
\hline - Evento/Periódico & - Abordagem da pesquisa \\
\hline - Principais autores & - Natureza da pesquisa \\
\hline $\begin{array}{l}\text { - Número de autores } \\
\text { por artigo }\end{array}$ & - Método de Pesquisa \\
\hline - Instituição & - Esfera Organizacional \\
\hline
\end{tabular}

Quadro 1: Modelo conceitual para análise Bibliométrica Fonte: Adaptado de Pinho e Lara (2008)

Cada variável do modelo conceitual busca apresentar as características da produção cientifica sobre o tema analisado nos eventos e periódicos da ANPAD no período de 1997 a 2013, conforme descrito a seguir:

a) ano da publicação: demonstra a evolução das publicações sobre internacionalização ao longo do período de análise;

b) evento/periódico: evidencia a distribuição da produção científica nos eventos e periódicos; c) autores: mostra os principais autores que publicaram sobre o tema no período de análise;

d) número de autores por artigo: apresenta a quantidade de autores por artigo;

e) instituição: apresenta as instituições a que estão vinculados os autores;

f) tipo de artigo: os artigos são classificados em teóricos ou empíricos;

g) abordagem da pesquisa: conforme a abordagem metodológica utilizada, as publicações são classificadas em quantitativas ou qualitativas, ou em ambas;

h) natureza da pesquisa: evidencia a natureza das publicações: exploratória, descritiva ou causal;

i) método de pesquisa: demonstra o método utilizado nos artigos: qualitativo ou survey;

j) esfera organizacional: apresenta a esfera abordada nas publicações, como: pública ou privada ou ambas; porém, nesta categoria, a classificação poderia ser não identificável, quando ela não era descrita, não estava implícita no conteúdo do estudo ou não se aplicava à realidade do trabalho.

\section{ApresentaÇão e Discussão dos Resultados}

Nos resultados, passa-se a apresentar as características gerais das publicações, seus aspectos metodológicos e, por fim, são descritas algumas características referentes à produção científica dos principais autores identificados no estudo.

Em relação ao número de publicações envolvendo a temática, a Figura 1 apresenta a quantidade de artigos publicados por ano relacionado ao tema.

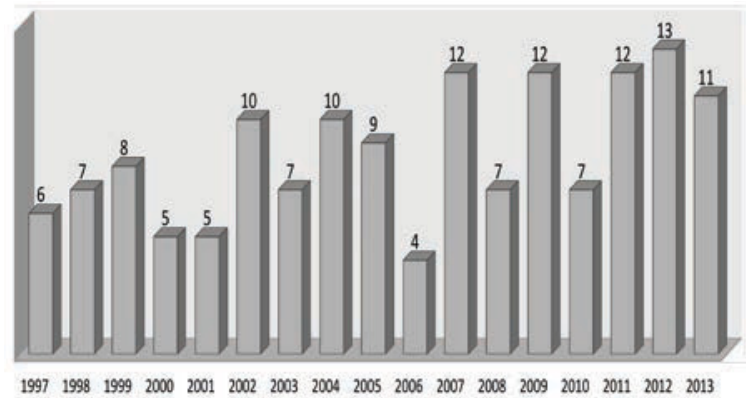

Figura 1: Quantidade de artigos publicados sobre comprometimento, entrincheiramento e consentimento de 1997-2013 Fonte: Dados da pesquisa 
Observa-se, pelas informações da Figura 1, uma tendência de aumento no número de artigos relacionados à temática, sendo que, em 2012, a produção atinge seu ápice em número de artigos para o período. Ainda, por meio da Figura 1, pode-se observar uma tendência de crescimento na produção científica relacionada ao tema. Esse crescimento da produção científica relacionada aos vínculos deve ser devido ao fato da pesquisa nacional sobre os vínculos, ter acompanhado o aumento progressivo do número de publicações internacionais de acordo com levantamento realizado para o período pelos próprios autores, na base de dados Web of Science (WOS), do Institute for Scientific Information (ISI), em julho de 2014. Os dados obtidos na WOS também demonstraram que a produção científica internacional relacionada ao comprometimento organizacional teve seu ápice no ano de 2012 (mesmo ano com maior produção em âmbito nacional).

O levantamento bibliométrico também demonstrou que nos últimos anos os estudos que questionam o modelo tridimensional de Meyer e Allen ganham força, havendo uma tendência de tratar o comprometimento normativo e o comprometimento instrumental como vínculos distintos do comprometimento organizacional. Assim, percebe-se, a partir de 2010 um movimento (ainda incipiente) da pesquisa nacional em tratar as três bases do modelo tridimensional como vínculos distintos. Assim, em 2010 surge o primeiro artigo sobre entrincheiramento e consentimento (apenas um artigo que tratou em conjunto dos três vínculos organizacionais - comprometimento, entrincheiramento e comprometimento). Em 2011 houve duas publicações envolvendo o entrincheiramento organizacional e o consentimento (uma delas envolveu o comprometimento e o entrincheiramento no mesmo artigo, e a outra abarcou os três construtos). Em 2012, foram três pesquisas sobre entrincheiramento e uma apenas sobre consentimento. Já em 2013 foram três publicações envolvendo o entrincheiramento organizacional, sendo que neste ano foi feita a primeira publicação sobre o tema em periódicos da ANPAD, neste caso, em específico, na RAC. É importante ressaltar que em todas essas publicações o comprometimento sempre esteve envolvido nos estudos. Até o momento não teve estudos apenas de entrincheiramento organizacional ou consentimento organizacional.

Com os dados apresentados na Tabela 1, constata-se que a cada seis anos ocorre um aumento em aproximadamente $5 \%$ na produção sobre o tema.
Tabela 1: Aumento da produção por período

\begin{tabular}{|c|c|c|c|}
\hline & Frequência & Percentual & $\begin{array}{c}\text { Percentual } \\
\text { Acumulado }\end{array}$ \\
\hline $1997-2002$ & 41 & 28,3 & 28,3 \\
\hline $2003-2008$ & 49 & 33,8 & 62,1 \\
\hline $2009-2013$ & 55 & 37,9 & 100,0 \\
\hline Total & 145 & 100,0 & \\
\hline
\end{tabular}

Fonte: Dados da pesquisa

Ao longo do período de análise, os artigos referentes à temática estiveram relacionados a diversos eventos da ANPAD, conforme demonstrado na Tabela 2:

Tabela 2: Artigos publicados por evento sobre o tema internacionalização

\begin{tabular}{|c|c|c|}
\hline Ano & Evento & $\begin{array}{c}\text { NúMERO DE } \\
\text { ARTIGOS }\end{array}$ \\
\hline 1997 & ENANPAD & 5 \\
\hline 1998 & ENANPAD & 6 \\
\hline 1999 & ENANPAD & 8 \\
\hline 2000 & ENANPAD & 4 \\
\hline 2001 & ENANPAD & 4 \\
\hline 2002 & ENANPAD & 7 \\
\hline 2002 & ENEO & 2 \\
\hline 2003 & ENANPAD & 5 \\
\hline 2004 & ENANPAD & 4 \\
\hline 2004 & ENEO & 3 \\
\hline 2004 & ENAPG & 2 \\
\hline 2005 & ENANPAD & 8 \\
\hline 2005 & 3 Es & 1 \\
\hline 2006 & ENANPAD & 4 \\
\hline 2007 & ENANPAD & 5 \\
\hline 2007 & ENGPR & 6 \\
\hline 2007 & ENADI & 1 \\
\hline 2008 & ENANPAD & 6 \\
\hline 2008 & ENEO & 1 \\
\hline 2009 & ENANPAD & 11 \\
\hline 2009 & ENGPR & 1 \\
\hline 2010 & ENANPAD & 4 \\
\hline 2010 & ENEO & 3 \\
\hline 2011 & ENANPAD & 11 \\
\hline 2012 & ENANPAD & 8 \\
\hline 2012 & ENEO & 2 \\
\hline 2012 & ENAPG & 2 \\
\hline 2013 & ENANPAD & 9 \\
\hline \multirow[t]{2}{*}{2013} & ENGPR & 1 \\
\hline & TOTAL & 134 \\
\hline
\end{tabular}

Fonte: Dados da pesquisa 
Constata-se que, no período de 1997 a 2013, a temática esteve relacionada aos eventos EnANPAD, EnEO, 3Es, ENAPG, ENGPR e ENADI. Considerando todo o período analisado, o evento que obteve o maior número de publicações relacionadas ao tema corresponde ao EnANPAD (109 artigos do total de 134), que consiste no maior evento da área de administração.
Ao verificar os artigos por periódicos, foram encontradas 11 publicações, sendo nove publicadas na RAC e duas na BAR. A RAC Eletrônica não apresentou nenhum artigo sobre o tema. A Figura 2 permite uma melhor visualização com relação à quantidade de artigos publicados relacionados às palavras-chave comprometimento, entrincheiramento e consentimento.

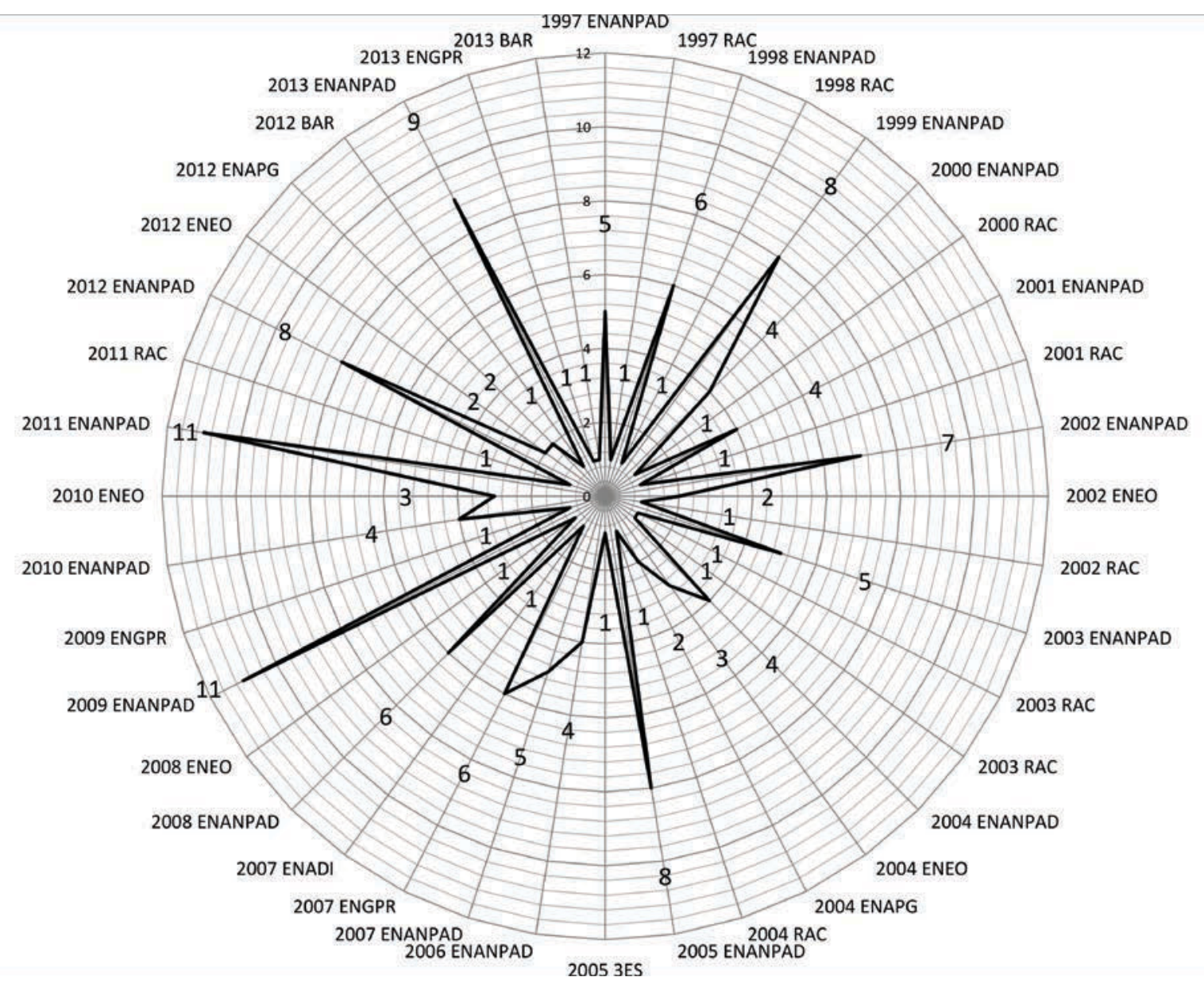

Figura 2: Artigos relacionados ao comprometimento, entrincheiramento e consentimento organizacionais por ano e por evento/periódico

Fonte: Dados da pesquisa

Os resultados também demonstraram que existe uma multiplicidade e diversidade quanto à autoria dos trabalhos, já que uma pequena parcela dos autores publicou um número elevado de artigos sobre a temática. Cabe ressaltar que, ao longo do período de análise, um autor se destaca com 24 trabalhos publicados; um autor com 12 trabalhos; um com nove; um autor com oito artigos publicados; um autor com seis artigos; três autores possuem cinco publicações cada um; sete autores possuem quatro artigos publicados cada um; e 11 autores possuem três publicações cada.

A quantidade de artigos publicados por autor e os principais pesquisadores relacionados ao tema encontram-se na Tabela 3. 
Tabela 3: Quantidade de artigos publicados por autor

\begin{tabular}{|c|c|}
\hline Autor & ARTigos PUBLICADOS POR AUTOR \\
\hline BASTOS, A. V. B. & 24 \\
\hline MEDEIROS, C. A. F. & 12 \\
\hline MARQUES, A. L. & 9 \\
\hline ALBUQUERQUE, L. G. & 8 \\
\hline MARQUES, G. M. & 6 \\
\hline ESTIVALETE, V. F. B. & 5 \\
\hline PINHO, A. P. M. & 5 \\
\hline RODRIGUES, A. C. A. & 5 \\
\hline ALMEIDA, G. O. & 4 \\
\hline BORGES-ANDRADE, J. E. & 4 \\
\hline BORGES, R. S. G. & 4 \\
\hline ENDERS, W. T. & 4 \\
\hline REGO, A. & 4 \\
\hline ROWE, D. E. O. & 4 \\
\hline SANCHES, E. N. & 4 \\
\hline BANDEIRA, M. L. & 3 \\
\hline CAMPOS, S. A. P. & 3 \\
\hline COSTA, V. M. F. & 3 \\
\hline FILENGA, D. & 3 \\
\hline HONÓRIO, L. C. & 3 \\
\hline PILATI, R. & 3 \\
\hline ROWE, D. E. O & 3 \\
\hline SCHEIBLE, A. C. F. & 3 \\
\hline SIQUEIRA, M. & 3 \\
\hline sOUTO, S. & 3 \\
\hline VEIGA, R. T. & 3 \\
\hline Outros & 224 \\
\hline
\end{tabular}

${ }^{1}$ Categoria "Outros": autores que tiveram número inferior a três artigos publicados

Fonte: Dados da pesquisa

Para os 145 artigos analisados, encontrou-se um total de 228 autores, constatando-se que há um número considerável de pesquisadores que publicam sobre o tema. Observa-se que 26 autores são aqueles que mais publicam sobre comprometimento. Esses 26 autores participaram de 135 artigos dos 145. Bastos, A. V. B. foi o que mais produziu sobre o tema com 24 artigos, seguido de Medeiros, C. A. F com 12 artigos.
Em relação à coautoria, constatou-se que os artigos analisados possuem no máximo seis autores, limite esse imposto pela própria ANPAD no momento de submissão dos artigos para seus eventos e periódicos. A Tabela 4 apresenta a relação entre a quantidade de artigos e o número de autores por artigo, sendo que a maioria dos artigos possui entre dois e três autores.

Tabela 4: Número de autores por artigo

\begin{tabular}{|c|c|}
\hline QUANTIDADE DE AUTORES & NúMERO DE ARTIGOS \\
\hline 1 & 20 \\
\hline 2 & 66 \\
\hline 3 & 36 \\
\hline 4 & 17 \\
\hline 5 & 5 \\
\hline 6 & 1 \\
\hline Total & 145 \\
\hline
\end{tabular}

Fonte: Dados da pesquisa

Destaca-se que 66 artigos possuem dois autores; 36 trabalhos possuem três autores; e 20 publicações possuem um autor. Esse fato demonstra que grande parte dos artigos relacionados ao tema é escrito em coautoria. Porém, ressalta-se que um número considerável das publicações foi desenvolvido por apenas um autor.

Também foram verificadas, com base nas informações declaradas pelos autores no momento da submissão dos artigos, as instituições que mais se destacaram em publicações, nos eventos e periódicos da ANPAD, no período de 1997 a 2013. A Tabela 5 apresenta as principais instituições tendo como base os 145 artigos analisados.

Tabela 5: Principais instituições.

\begin{tabular}{|c|c|}
\hline INSTITUIÇão & $\begin{array}{c}\text { NúMERO DE } \\
\text { PUBLICAções } \\
\text { VINCULADAS }\end{array}$ \\
\hline Universidade Federal da Bahia & 31 \\
\hline Universidade Federal de Minas Gerais & 15 \\
\hline Universidade Federal do Rio Grande do Norte & 12 \\
\hline Universidade de São Paulo & 9 \\
\hline Universidade Federal de Santa Maria & 8 \\
\hline
\end{tabular}




\begin{tabular}{|c|c|}
\hline Universidade Federal de Santa Catarina & 6 \\
\hline Universidade de Brasília & 6 \\
\hline Universidade Federal do Rio de Janeiro & 5 \\
\hline Universidade Metodista de São Paulo & 5 \\
\hline Universidade de Aveiro & 4 \\
\hline Universidade Federal da Paraíba & 4 \\
\hline Universidade Federal de Pernambuco & 4 \\
\hline Universidade Estadual de Minas Gerais & 3 \\
\hline Outros & 33 \\
\hline
\end{tabular}

${ }^{1}$ Categoria "Outros": instituições que tiveram um número inferior a três artigos publicados

Fonte: Dados da pesquisa

Os resultados obtidos demonstram que as instituições que obtiveram um maior número de publicações relacionadas à produção envolvendo o comprometimento, entrincheiramento organizacionais e consentimento foram: a Universidade Federal da Bahia com 31 publicações; a Universidade Federal de Minas Gerais relacionada a 15 publicações; e a Universidade do Rio Grande do Norte com 12 publicações; seguidas da Universidade de São Paulo com nove publicações, da Universidade Federal de Santa Maria com oito publicações e Universidade Federal de Santa Catarina e Universidade de Brasília, ambas com seis publicações.

Em relação aos aspectos metodológicos das publicações, verificou-se que a maioria dos artigos é de cunho empírico (94,5\%). Os estudos teóricos são em menor número $(5,5 \%)$, indicando uma menor frequência de sistematizações e reflexões para o desenvolvimento conceitual dos construtos investigados. Dos artigos classificados como teóricos, um é do tipo Bibliométrico sugerindo a ausência de estudos com interesse de levantar informações acerca da produção científica sobre o tema. Esse artigo, com o título "Comprometimento organizacional: o estado da arte da pesquisa no Brasil", foi primeiramente publicado em 2002, por Medeiros, C. A. F. et al. no ENANPAD, e, posteriormente, republicado na RAC em 2013.

Ainda verificou-se que, dos 137 artigos de campo, 104 tiveram uma abordagem quantitativa, 21 qualitativa e 12 uma abordagem qualitativa e quantitativa. A predominância da abordagem quantitativa demonstra que as pesquisas relacionadas ao tema, em sua maioria, buscam a generalização dos resultados.
Como consequência dessa escolha metodológica, prevaleceu entre os estudos o uso de questionários e escalas como instrumentos de coleta de dados. São poucas as pesquisas que acrescentam instrumentos como entrevistas ou análises documentais.

Dentre os artigos analisados, destacam-se por serem, em sua maioria, os artigos de natureza descritiva (88 artigos ou $64,2 \%$ ). Estudos classificados como causal foram um total de 25 ou $18,2 \%$, e estudos exploratórios foram um total de 20 artigos ou 14,6\%. Estudos classificados como de natureza descritiva e exploratória somaram um total de 4 artigos $(2,9 \%)$. A prevalência de artigos de natureza descritiva e causal, respectivamente, corrobora com a predominância de publicações de abordagem quantitativa.

Por fim, verificou-se que $67,2 \%$ dos artigos são do tipo survey, e os $32,8 \%$ restantes foram classificados como estudo de caso.

A Tabela 6 apresenta a classificação dos artigos de acordo com a esfera organizacional a que estão relacionados.

Tabela 6: Classificação dos artigos de acordo com a esfera organizacional relacionada

\begin{tabular}{|c|c|c|}
\hline Esfera Organizacional & Frequência & Percentual \\
\hline PRIVADA & 84 & 61,3 \\
\hline PÚBLICA & 21 & 15,3 \\
\hline PÚBLICA / PRIVADA & 21 & 15,3 \\
\hline $\begin{array}{c}\text { NÃO IDENTIFICÁVEL } \\
\text { / NÃO SE APLICA }\end{array}$ & 11 & 8,0 \\
\hline Total & 137 & 100,0 \\
\hline
\end{tabular}

Fonte: Dados da pesquisa

Evidenciou-se que, de modo geral, os artigos da amostra relacionam-se à esfera organizacional privada, sendo que uma pequena parcela está relacionada ao setor público ou relacionada a ambas as esferas, pública e privada. Em $8 \%$ não foi possível identificar a esfera organizacional, tendo em vista que em alguns casos o trabalho não permitia a identificação e em outros o foco do artigo não estava relacionado ao contexto organizacional.

Por fim, com o intuito de conhecer melhor as características das publicações dos principais autores destacados neste estudo, foram cruzados os tipos de publicações e instituições relacionadas aos artigos 
publicados pelos 26 autores. Verificou-se que apenas quatro dos principais autores sobre o tema publicaram artigos teóricos, são eles: Bastos, A. V. B.; Medeiros, C. A. F; Albuquerque, L. G. e Sanches, E. N. Cada autor publicou apenas um artigo teórico. Também evidencia-se que os principais autores, de modo geral, estão vinculados à Universidade Federal da Bahia, à Universidade Federal do Rio Grande do Norte, à Universidade Federal de Minas Gerais, à Universidade de São Paulo, à Universidade Federal de Santa Maria e à Universidade de Brasília.

\section{Considerações Finais}

Com base na análise dos artigos relacionados às palavras-chave "comprometimento", "entrincheiramento" e "consentimento", publicados nos eventos e periódicos da ANPAD, no período de 1997 a 2013, constata-se que houve um aumento nas publicações nacionais sobre os vínculos do indivíduo com a organização, acompanhando a tendência internacional de crescimento de publicações sobre o tema comprometimento organizacional.

Ainda, é possível verificar que a maior parte dos estudos utilizou o modelo proposto por Meyer e Allen (1991) ou medidas multidimensionais fortemente influenciadas por ele. Já durante os últimos anos do período analisado, apesar da clara hegemonia do modelo de Meyer e Allen, observa-se um aumento crescente de estudos questionando esse modelo. Assim, a partir de 2010, ganha força um movimento (ainda incipiente) de pesquisadores brasileiros em tratar as três bases do modelo tridimensional como vínculos distintos com o objetivo de resolver alguns dos problemas conceituais e empíricos trazidos pelo modelo tridimensional.

É possível verificar, ainda, que o evento que obteve maior número de publicações relacionadas ao tema corresponde ao EnANPAD, maior evento nacional da área de administração. No que se refere aos periódicos, foram publicados apenas 11 artigos relacionados ao tema na RAC e BAR conjuntamente.

Os artigos possuem no máximo seis autores, limite esse imposto pela própria ANPAD, sendo que a maioria das publicações têm entre dois e três autores demonstrando uma tendência de pouca cooperação entre os pesquisadores da área. As instituições que mais se destacaram foram a Universidade Federal da Bahia, a Universidade Federal de Minas Gerais, a Universidade do Rio Grande do Norte, a Universidade de São Paulo e a Universidade Federal de Santa Maria. A Universidade Federal da Bahia tem destaque devido ao pesquisador Antônio Virgílio Bittencourt Bastos, referência sobre o tema e autor com maior número de publicações no período analisado. Além disso, esse autor é o líder do grupo de pesquisa Indivíduo, Organizações e Trabalho, responsável pelo desenvolvimento dos conceitos de Entrincheiramento Organizacional - ver Rodrigues (2009) - e Consentimento Organizacional - ver Silva (2009).

Os artigos analisados são em sua maioria empíricos, predominando a abordagem quantitativa com natureza descritiva, e estão relacionados principalmente ao setor privado. Predominam os surveys, com coleta de dados por meio de instrumentos padronizados $e$ validados. Há um pequeno contingente de estudos qualitativos ou que combinam as duas abordagens. Tais resultados são muito semelhantes aos encontrados por Bastos et al. (2014) e enfatizam a necessidade de uma maior sistematização e desenvolvimento teórico dos construtos a fim de reduzir a confusão conceitual que permeia o tema.

Os resultados desta pesquisa contribuem para a construção do conhecimento científico a cerca dos vínculos do indivíduo com a organização, uma vez que demonstraram as principais características e tendências com relação às publicações acadêmicas sobre o assunto nos eventos e periódicos vinculados a ANPAD. Por fim, sugere-se que estudos futuros desta natureza possam ter uma maior amplitude abrangendo outros eventos e periódicos nacionais e internacionais.

\section{REFERÊNCIAS}

ASSOCIAÇÃO NACIONAL DE PÓS-GRADUAÇÃO E PESQUISA EM ADMINISTRAÇÃO - ANPAD. Sobre a

ANPAD. 2009. Disponível em: < http://www.anpad.org. br/sobre_apresentacao.php >. Acesso em: $1^{\circ}$ jun. 2010.

ASSOCIAÇÃO NACIONAL DE PÓS-GRADUAÇÃO E PESQUISA EM ADMINISTRAÇÃO (ANPAD). Eventos.

2010a. Disponível em: <http://www.anpad.org.br/eventos. php>. Acesso em: $1^{\circ}$ jun. 2010. 
ASSOCIAÇÃO NACIONAL DE PÓS-GRADUAÇÃO E PESQUISA EM ADMINISTRAÇÃO (ANPAD).

Publicações. 2010b. Disponível em: < http://www.anpad. org.br/eventos.php>. Acesso em: 1 de jun. 2010.

BARROS, A. R. O. Comprometimento organizacional: um estudo de suas relações com práticas de gestão e intenção de permanência. 2007.147 f. Dissertação (Mestrado em Administração) - Universidade Federal da Bahia, Salvador, 2007.

BASTOS, A. V. B. et al. Vínculos dos Indivíduos com a Organização: Análise da Produção Científica Brasileira 2000-2010. Psicologia: Teoria e pesquisa, [S.I.], v. 30, n. 2, p. 153-162, 2014.

BASTOS, A. V. B. et al. Comprometimento no trabalho: fundamentos para a gestão de pessoas. In: BORGES, L. O.; MOURÃO, L. O trabalho e as organizações: atuações a partir da psicologia. Artmed: 2013. p. 279-310.

BASTOS, A. V. B. et al. Comprometimento, consentimento ou entrincheiramento? Um estudo comparativo entre categorias ocupacionais e contextos organizacionais. Relatório final apresentado ao CNPQ. Bahia: Salvador, 2009.

BASTOS, A. V. B.; MENEZES, I. G. Bases sociológicas, antropológicas e psicológicas do comprometimento organizacional. Psicologia em Revista, [S.l.], v. 15, n. 3, p. 200-215, 2009.

BASTOS, A. V. B. et al. Comprometimento organizacional. In: SIQUEIRA; M. M. M. (Org.) Medidas decomportamento organizacional: ferramentas de diagnóstico e de gestão. Porto Alegre: Artmed, 2008. p. 49-96.

CARSON, K. D.; BEDEIAN, A. G. Career commitment: Construction of a measure and examination of its psychometric properties. Journal of Vocational Behavior, [S.I.], v. 44, n. 3, p. 237-262, 1994.

CARSON, K. D.; CARSON, P. P.; BEDEIAN, A. G. Development and construct of a career entrenchment measure. Journal of Occupational and Organizational Psychology, [S.I.], v. 68, p. 301-320, 1995.

COSTA, F. M.; BASTOS, A. V. B. Múltiplos comprometimentos no trabalho: um estudo entre trabalhadores de organizações agrícolas do polo de fruticultura irrigada de Juazeiro/Petrolina. Revista de

Administração UFSM, [S.1.], v. 2, n. 2, p. 280-297, 2009.
COSTA, V. M. F. et al. Comprometimento organizacional: confrontando suas diferenças entre empresas e trabalhadores da agroindústria do polo Juazeiro/Petrolina. In. ENCONTRO NACIONAL DE PÓS-GRADUAÇÃO E PESQUISA EM ADMINISTRAÇÃO, 32. Anais... Rio de Janeiro: ANPAD, 2008. p. 1-16.

COSTA, V. M. F. As bases afetiva e instrumental do comprometimento Organizacional: confrontando suas diferenças entre empresas e trabalhadores da agricultura irrigada do Pólo Juazeiro/Petrolina. 2007. 269f. Tese (Doutorado em Administração) - Universidade Federal da Bahia, Bahia, 2007.

GIL, A. C. Métodos e técnicas de pesquisa social. São Paulo: Atlas, 2010.

MACEDO, M. A. S.; CASA NOVA, S. P.; ALMEIDA, K.

Mapeamento e análise bibliométrica da utilização da análise envoltória de dados (DEA) em estudos das áreas de contabilidade e administração. In: ENANPAD, 23, 1999, Foz do Iguaçu. Anais... Foz do Iguaçu: ANPAD, 1999. p. 1-16.

MEYER, J. P.; ALLEN, N. J. A three-component conceptualization of organization commitment. Human Resource Management Review, [S.I.], v. 1, n. 1, p. 6198, 1991.

MEYER, J. P.; HERSCOVITCH, L. Commitment in the workplace: toward a general model. Human Resource Management Review, [S.1.], v. 11, p. 299-326, 2001.

MYERS, D. Psicologia Social. Rio de Janeiro: Editora LTC, 2000.

MOSCON, D.C. B.; SOUZA, J.J. Olhar da liderança sobre o conceito de comprometimento com uma crítica ao modelo tridimensional. In: ENCONTRO NACIONAL DE PÓS-GRADUAÇÃO E PESQUISA EM ADMINISTRAÇÃO, 34. Anais... Rio de Janeiro: ANPAD, 2010. p. 1-17.

MOWDAY, R. T.; PORTER, L. W.; STEERS, R. M. The measurement of organizational commitment. Journal of Vocational Behavior, [S.I.], n. 14, p. 224-247, 1979.

NASCIMENTO A. L. do. Comprometimento no Trabalho: Percepção sobre o Construto e sua Influência na Prática Cotidiana de Gestores Públicos In: ENCONTRO NACIONAL DE PÓS-GRADUAÇÃO E PESQUISA EM ADMINISTRAÇÃO. Anais... Rio de Janeiro: ANPAD, 2013. p. 1-16. 
PINHO, A. P. M. Comprometimento,

entrincheiramento e consentimento organizacionais:

uma análise desses vínculos, entre gestores e

trabalhadores, em contextos público e privado. 2009. 258

f. Tese (Doutorado em Administração) - Universidade

Federal da Bahia, Salvador, BA, 2009.

PINHO, A. P. M.; BASTOS, A. V. B; ROWE, D. E.

O. A Articulação Entre Vínculos Organizacionais:

Comprometimento, Entrincheiramento e Consentimento.

In: ENCONTRO NACIONAL DE PÓS-GRADUAÇÃO E PESQUISA EM ADMINISTRAÇÃO. Anais... Rio de Janeiro: ANPAD, 2012. p. 1-16.

. Comprometimento, Entrincheiramento e

Consentimento Organizacionais: explorando seus

determinantes e consequentes entre gestores. In:

ENCONTRO NACIONAL DE PÓS-GRADUAÇÃO E

PESQUISA EM ADMINISTRAÇÃO. Anais... Rio de

Janeiro: ANPAD, 2011. p. 1-16.

PINTO, M. de R.; LARA, J. D. O que se publica sobre comportamento do Consumidor no Brasil, afinal? Revista de Administração da UFSM, [S.l.], v. 1, n. 3, p. 85-102, 2008 .

RODRIGUES, A. C de A. et al. Como se Constroem e se Desenvolvem o Entrincheiramento e o Comprometimento com a Organização: Análise Qualitativa de Diferentes Trajetórias Profissionais. In: ENCONTRO NACIONAL DE PÓS-GRADUAÇÃO E PESQUISA EM ADMINISTRAÇÃO. Anais... Rio de Janeiro: ANPAD, 2013. p. 1-16.

RODRIGUES, A. C. de A.; BASTOS, A. V. B. Do comprometimento de continuação ao entrincheiramento organizacional: evidências da sobreposição entre os construtos. In: ENCONTRO NACIONAL DE PÓSGRADUAÇÃO E PESQUISA EM ADMINISTRAÇÃO, 35, 2011, Rio de Janeiro. Anais... Rio de Janeiro: ANPAD, 2011. CD-ROM.

Problemas Conceituais e Empíricos na Pesquisa sobre Comprometimento Organizacional: uma Análise Crítica do Modelo Tridimensional de J. Meyer e N. Allen. Revista Psicologia: Organizações e Trabalho, [S.l.], v. 10, n. 2, p. 129-144, 2010.

\section{RODRIGUES, A. C. A. Do comprometimento de} continuação ao entrincheiramento organizacional: o percurso de validação da escala e análise da sobreposição entre os construtos. 2009. 212 f. Dissertação (Mestrado em Psicologia) - Universidade Federal da Bahia, Bahia, 2009.

ROSTAING, H. La bibliométrie et sés techniques.

Toulouse: Sciences de la Société; Marseille: Centre de Recherche Rétrospective de Marseille, 1997.

ROWE, D. E. O.; BASTOS, A.V. B. Múltiplos comprometimentos e suas relações com o desempenho: um estudo entre docentes do ensino superior brasileiro em IES públicas e privadas. 2008. 244 f. Tese (Doutorado em Administração) - Universidade Federal da Bahia, Salvador, BA, 2008.

SCHWARTZ, S. H.. Valores humanos básicos: seu contexto e estrutura intercultural. In: TAMAYO, A.; PORTO, J. B. (Org.) Valores e comportamento nas organizações. Petrópolis, RJ: Vozes, 2005. p. 21- 55.

SILVA, E. E. C. Consentimento organizacional: uma proposta de medida do construto. 2009. 168 f.Dissertação (Mestrado em Psicologia) - Universidade Federal da Bahia, Bahia, 2009.

\section{SILVA, M. R. Análise bibliométrica da produção} científica docente do programa de pós-graduação em educação especial/UFSCar: 1998-2003.2004.

177 f. Dissertação (Mestrado em Educação Especial) Universidade Federal de São Carlos, São Carlos, 2004.

TRIVIÑOS, A. N. S. Introdução à pesquisa em ciências sociais: a pesquisa qualitativa em educação. São Paulo: Atlas, 1987. 